This item was submitted to Loughborough's Research Repository by the author.

Items in Figshare are protected by copyright, with all rights reserved, unless otherwise indicated.

\title{
Digital technologies and learning in physical education: pedagogical cases [Book Review]
}

PLEASE CITE THE PUBLISHED VERSION

https://doi.org/10.1080/13573322.2017.1394836

PUBLISHER

(C) The Author. Published by Taylor \& Francis (Routledge)

\section{VERSION}

AM (Accepted Manuscript)

\section{PUBLISHER STATEMENT}

This work is made available according to the conditions of the Creative Commons Attribution-NonCommercialNoDerivatives 4.0 International (CC BY-NC-ND 4.0) licence. Full details of this licence are available at: https://creativecommons.org/licenses/by-nc-nd/4.0/

\section{LICENCE}

CC BY-NC-ND 4.0

\section{REPOSITORY RECORD}

Sargent, Julia. 2019. "Digital Technologies and Learning in Physical Education: Pedagogical Cases [book Review]”. figshare. https://hdl.handle.net/2134/27322. 


\section{Book review}

Digital Technologies and Learning in Physical Education: Pedagogical Cases, Ashley Casey, Victoria A. Goodyear \& Kathleen M. Armour (eds.), 2017 London, Routledge

$£ 37.99$ (paperback), 276 pp.

ISBN 978-1-138-94729-0

\section{Julia Sargent}

School of Sport, Exercise and Health Sciences, Loughborough University, Loughborough, UK.

Email: j.sargent@lboro.ac.uk

ORCiD ID: orcid.org/0000-0001-9082-8378

Twitter Handle: @julia_sargent 


\begin{abstract}
Digital technology has been the focus of recent debates in physical education with questions being considered about its influence on pedagogy and the future of the subject. Yet, there is scant knowledge about how digital technologies are being used by teachers and whether their use has influenced students learning. 'Digital Technologies and Learning in Physical Education: Pedagogical Cases’ focuses on expanding the knowledge about the ways in which digital technologies are being used by teachers to support and enhance young peoples' learning in physical education. The premise of the book is to develop the understanding of pedagogy and digital technology in education. Furthermore, it seeks to encourage critical reflection on the use of digital technology in physical education. This book review explores the central ideas of the book, its approach and an evaluation of its content.
\end{abstract}

Key Words: Digital technology; pedagogy; physical education; teaching; digital learning 
Digital technology has been the 'hot topic' of recent debates in physical education with questions being considered about its influence on pedagogy and the future of the subject (Gard 2014; Lupton 2015). Despite the increasing availability of resources and critical discussion in this area, many questions remain among professionals in physical education. 'Digital Technologies and Learning in Physical Education: Pedagogical Cases' focuses on expanding the knowledge base in the area by exploring the ways in which digital technologies can be used by teachers to support and enhance young peoples' learning. In addressing this gap, the aim of the book was to 'contribute towards a wider understanding of pedagogy and technology in physical education’ (p.2) and to 'open a debate in physical education to consider the potential impact of educational technologies on the pedagogies of our subject' (p.5).

On opening the book and exploring its contents, I was intrigued by the breadth and diversity of its contributors. Scanning the authors, the reader is greeted with academics from disciplines such as anthropology, psychology and literacy from a vast array of national contexts. This mixture of perspectives, therefore, keeps the international reader in mind and illustrates the application of digital technology (and importantly the pedagogical challenges involved) as applicable across a variety of physical education contexts. This variety is a commendable strength of these narratives as they reveal how multifaceted and complex the experiences and analyses of digital technology can be.

The editors, Ashley Casey, Victoria Goodyear and Kathleen Armour have compiled fifteen chapters. The first chapter (written by the editors) introduces the rationale for the book, the key concept of 'pedagogies of technology' that are fundamental to understanding the approach taken to the case narratives, and the use of a pedagogical cases model. The rationale for the book emphasises the need to explore the effects of 
digital technologies on teachers' pedagogies and to take discussions regarding pedagogy forward in new ways. They conceptualise pedagogies of technology as pedagogies which maximise the latent potential of digital technologies to accelerate learning in meaningful ways that meet the needs of learners. The key point made in regards to this concept is that the development of pedagogies of technology requires pedagogues to understand the interactions that occur between teacher, learner and curriculum and envision how digital technology could enhance this process. In other words, considering pedagogy before technology.

In using this concept as a basis for the case narratives, the teachers were given some guidance notes to reflect upon both pedagogy and technology. The premise of this guide was to ensure that teachers focused on explaining the pedagogies they found effective when using technology. In seeking to combine both practice and theory/research, they use the innovative and novel 'pedagogical cases framework' (see Armour 2014) to explore thirteen teachers' narratives. The personalised title of each of the thirteen teachers’ chapters (for example Chapter 3, Jamie: ‘I couldn’t teach without technology'), forefronts the teacher that lies at the heart of each case narrative. This emphasises the model whereby the practice drives the analyses. Each of the thirteen case chapters follows a similar format that can be broken down into six distinct stages. It starts with a physical education teacher narrative that describes their practice where digital technology is used (or not used). A multidisciplinary team comprising of three academics then analyses the teacher narrative based on their disciplinary perspective. The pedagogue (and lead author), then attempts to draw the strands of each case together, highlighting key themes, questions and lessons to be learned from the case. This is followed by the teacher critically reflecting on the perspectives presented by the analysis team. Each case chapter concludes with a concise bullet pointed summary of 
'lessons learned from the case'. This gives the reader some useful key messages to take away from the chapter.

The pedagogical cases approach 'hoped to develop new thinking around pedagogies of technology that were grounded in both theory and practice' (p.3). I believe that the authors succeeded in this through the variety of analyses that stayed in line with the narratives of the teacher. However, given that the text is intended as a resource for students of physical education, the concluding section could have been strengthened further with key terms, further reading, useful links or critical questions.

The variety between each teacher's experiences and use of digital technology is a particularly interesting feature. Whether it be Chapter 14, 'Jacob and Martin’ who illustrate how digital technologies are experienced by physical education teacher education (PETE) students in Sweden, or Chapter 9, 'Lynne’ who used technology to help promote messages regarding health in America, the replicated structure of each chapter, is such that any chapter can be read in isolation. This gives the reader a sense of freedom in exploring a chapter that resonates with his or her own interests and experiences. However, as stated by the editors, 'this is not a technology book' (p.1). It does not list step by step guides or detailed plans of how to use digital technology in physical education. Its strength lies in its depth of analysis by both academics and teachers. For example, Chapter 7, ‘Andy’ considers the visions and realities of Andy’s decision to consider blogging with his primary physical education students. The pedagogical perspective provided by Tim Fletcher highlights how Andy does not put his visions of using blogging into his practice. Nonetheless, this echoes Shawn Bullock's sentiment (Chapter 7) that shows how there is much to learn about teaching (as well as learning) when using technology. Andy's narrative refreshingly highlights how 
pedagogical practice with technology involves teachers making critical decisions about 'why, how and when to use (and not use) specific technologies' (p.114). All of which are important pedagogical decisions.

The almost cyclical nature of each chapter allows the reader to sequentially understand, analyse and evaluate the narrative. Yet, as the editors also acknowledge, (see Casey, Goodyear and Armour 2017), there is little in the cases that was genuinely radical or innovative. However, it is difficult to 'be brave' (p.250) in our thinking around digital technology when we are comfortable in the debates and environments in which we write. The perspectives of policy makers, businesses, health professionals, technology experts, students, parents, and the wider (non-academic) community may have enabled the authors to more deeply explore the links between theory, practice and context of physical education.

In considering the lessons learnt across the case study chapters, the editors conclude the book by commenting on three areas: (i) new information to help conceptualise pedagogies of technology, (ii) a challenge for pedagogues to 'be brave' (iii) and suggestions for the future. In summarising the themes regarding pedagogies of technology across the book, the editors conclude that digital technology is a tool for teaching and learning, a tool that can promote a student-centred approach and involves teacher learning at the heart of the process. At first glance, this seems relatively obvious. Yet, the editors and the chapter authors can be commended in their analysis by extending an invitation to the field to be brave in their thinking around digital technology. Their reflections in relation to the impact of digital technology on recorded data, health messages, the body and social media, therefore, goes broader than just considering digital technology within the four walls of the gym or classroom. 
In considering the future of this area, the editors state the need to pose questions about 'how the infrastructure of education can be changed to do things that were previously thought impossible and impractical' (p.256). As shown by the analyses in this book, this is not an easy task, but one that this assemblage of ideas has begun to unpick and debate.

As an early career researcher, I found the book to be a thoroughly engaging example of the links between practice, theory and research and invaluable in developing our understanding of the messy realities of digital technology use in physical education and its relationship with pedagogy. The multi-disciplinary perspectives come to the fore in the chapter authors' interpretation and analyses of the teacher's narrative. Using research, theoretical perspectives and critical commentary, they provide a viewpoint that, in some cases, aligns with that of the teacher. In other instances, they provide contrasting and challenging statements that focus on the effectiveness of the practice-based examples to challenge the teacher in their reflection. From reading the practitioner reflection based on these analyses, it is clear that these insights have been valuable in their understanding of their practice and a vehicle in which to engage with their own personal development. These perspectives are presented and written in an accessible but academic format that forces one to think critically about how and why digital technology is used (or not used). It introduced thought provoking ideas and perspectives that for teachers, researchers and students alike can stimulate debate and opportunities for professional learning.

\section{References}

Armour, K. M. (Ed.). (2014). Pedagogical cases in physical education and youth sport. Oxon: Routledge.

Casey, A., Goodyear, V.A., \& Armour, K. M. (2017). Rethinking the relationship between pedagogy, technology and learning in health and physical education. Sport, Education and Society, 22(2), 288-304. doi: 10.1080/13573322.2016.1226792 
Gard, M. (2014). eHPE: a history of the future. Sport, Education and Society. 19(6), 827-845. doi: 10.1080/13573322.2014.938036

Lupton, D. (2015). Data assemblages, sentient schools and digitised health and physical education (response to Gard). Sport, Education and Society, 20(1), 122-132. doi:

$10.1080 / 13573322.2014 .962496$ 